\title{
Environmental Policy and Science Management: Using a Scientometric-specific GIS for E-learning Purposes
}

\author{
N.D. Hasanagas, A.D. Styliadis, E.I. Papadopoulou
}

\author{
Nikolaos D. Hasanagas, Ahanasios D. Styliadis \\ Kavala Institute of Technology, Department of Landscape Architecture \\ City of Drama, Greece, GR 66100 \\ Email: styliadis@ath.forthnet.gr, nikolaos.hasanagas@gmail.com

\section{Eleni I. Papadopoulou} \\ Aristotle University of Thessaloniki, Faculty of Agricultural Science \\ Department of Agricultural Economics, City of Thessaloniki, GR 54124 \\ E-mail epapa@agro.auth.gr
}

\begin{abstract}
:
Who is the "good scientist" in rural-environmental policy? This is not so self-evident as in the case of private high-tech industry. Developing e-learning system in environmental science management is a challenging task in the area of forest and general rural development policy. Who determines the most "important" scientific information and who controls it? There are algorithms for measuring centrality in information networks. The concepts of closeness and betweenness centrality are used as basic metadata for categorizing the communication type in the rural-environmental policy networks. This paper discusses the development of a GIS-based model which includes region-based scientometrics, regarding policy field communication.

Keywords: region-based scientometrics, GIS e-Learning, forest policy, integrated rural development policy, environmental policy, complete network analysis, policy making.
\end{abstract}

\section{Introduction}

It is evident that in high-tech policy sector, "good scientist" is the private industry, since impressive products like mobile phones are usually produced by the industry and not by universities or public agencies. However, this is not the case in rural-environmental policy, where the main issues are about "multiple-use forestry", "nature protection", "integrated rural development", "sustainability" etc, as in these abstract issues, success normally means to persuade about who the "trouble-maker" and who the "rescuer" is and not to find concrete solutions. Moreover, despite the common belief that universities or research institutes are the most influential suppliers and controllers of "scientific" information, this is also not necessarily the rule in rural-environmental policy.

This paper presents the possibility of developing a pattern of scientometric-specific GIS -based model, which is going to be applicable in e-learning for various target groups (e.g. students who are specialized in forest policy and rural policy analysis, lobbyists, policy makers). In the context of this paper, "scientometric" differs from the classical measurements of citation rates or implementation of academic bibliography. It is defined as the management of information which is regarded as "scientific" by lobbyists, public administrators and academics in networks of forest policy issues which are used as case studies in this paper.

The complete network analysis conducted here by VISONE software showed that the "scientific" information, which is regarded as most "important" in a network, is often supplied by practitioners, such as environmental and forest agencies, landowner organizations etc, and not necessarily by actors officially entitled as "scientific", such us universities or research centers. This implies that the "scientific" is rather a feeling induced by factors different from the official orientation of an actor. The analysis pointed out that forest policy, environmental issues and rural development are inseparable policy fields and strongly integrated with each other.

The actors who produce "scientific" information, which is considered to be "important", can disseminate the information which is favorable for them, in order to support their socio-political positions. Thus, a "scientifically important" actor may be an informal but influential decision-maker. Additionally, the network will collapse, if an actor who participates in many information paths and thus controls the flow of information, suddenly abandons the network. In this case, the actor is merely a crucial "postman" but not necessarily a "decision-maker". In policy 
planning, implementation and evaluation, it is useful to distinguish the "decision-maker" from the "postman" in order to focus the lobbying activity on the former rather than on the latter. This is especially useful in integrated rural development, incl. forest policy, as there are numerous complex, informal and different procedures among the countries and unclear indicators (RUDI research project findings). Therefore, there is a point in developing an adaptive GIS e-learning system on region-specific information networks in order to make lobbyists, public administrators and students more familiar with science management in policy arena [14].

\section{Selecting the GIS Learning Object and the learner target group}

Adaptive learning systems are supposed to require numerous and elaborated rules $[5,6,18]$. However, the existence of tested algorithms which detect the position of an actor in the formal or informal hierarchy of information in a network simplifies the rules and metadata requirements, even in complex social systems $[6,8,11,16,19]$. Two algorithms, "closeness centrality" (cc) and "centrality of betweenness" (cb), can be used for classifying the actors. The only question is which type of actors interests each learner group [2, 11, 17, 6, 9]. We can distinguish two aggregated and seven specific learner groups:

A) Aggregated learner groups: 1) State actor employees (civil servants of agencies), 2) Private actor employees (lobbyists, managers, experts and employees of interest groups or enterprises)

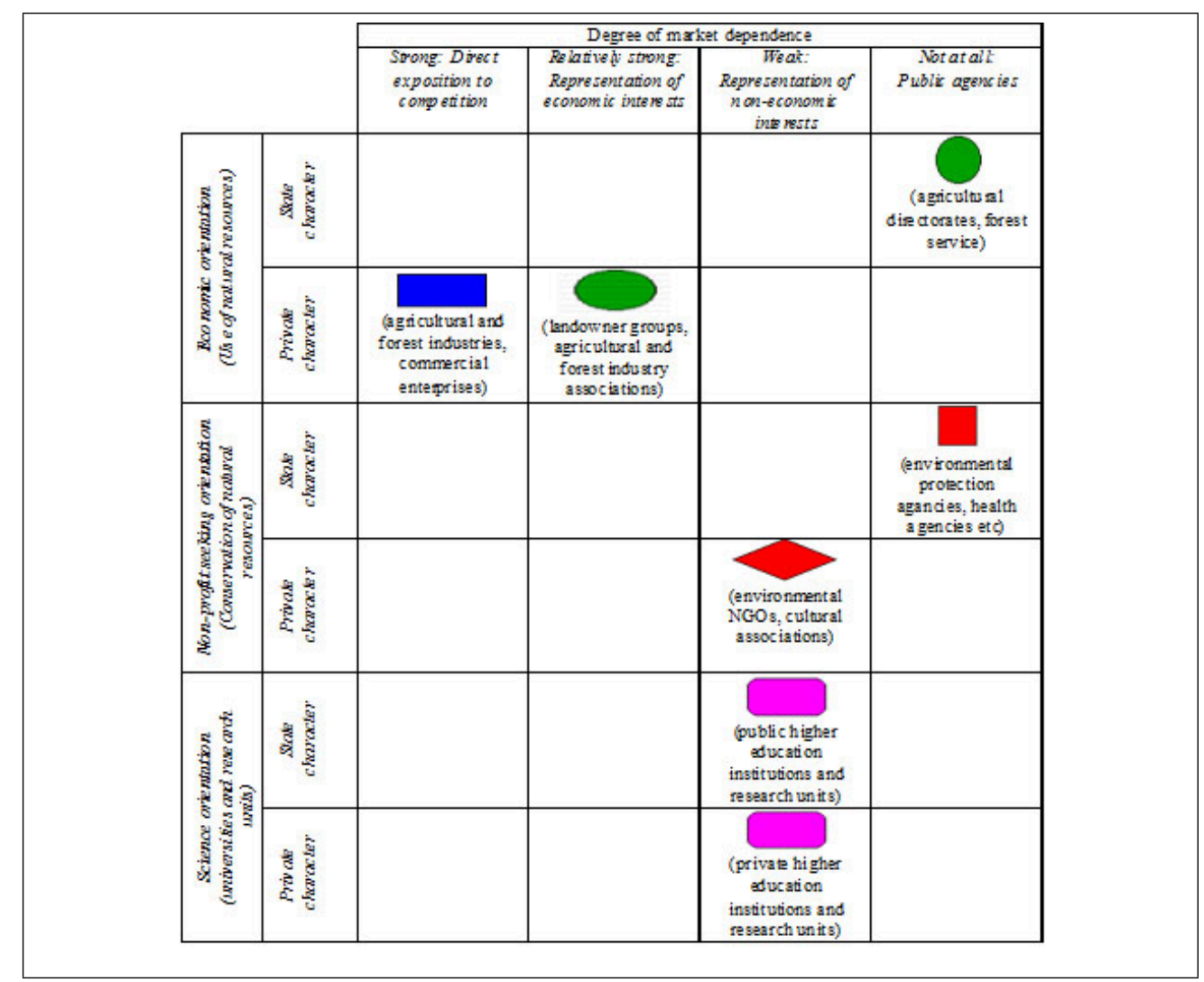

Figure 1: Learner target groups.

B) Specific learner target groups (Figure 1): These emerge by the combination of three dimensions [12, 13, 15]: 1) the legal character of the actor (public or private), 2) the orientation of the actor (economic or non-profit seeking regarding the management of natural resources, or science-orientation), and 3) the degree of dependence on the liberal market (i. individual enterprises which are directly exposed to the competition, ii. economic interest groups of enterprises which only represent their interests in the policy network, iii. non-profit seeking interest groups such as cultural association for the renovation of villages, forest recreation, and environmental NGOs, which only depend on national and EU funds, or private universities and research centres which can be flexible to the market needs, and iv. state actors which are totally independent from the market, such as agencies, public universities and 
research units) (RUDI findings).

The GIS learning objects (Figure 2) are the seven actor types described in Figure 1 ("Archimedes" research project findings), in each category of information management function (cc and cb). An enterprise characterized by high cc (strong "decision-maker") in a certain region-specific policy network is a case of learning object, while the same enterprise characterized by a low cb (weak "postman") is a different case of learning object.

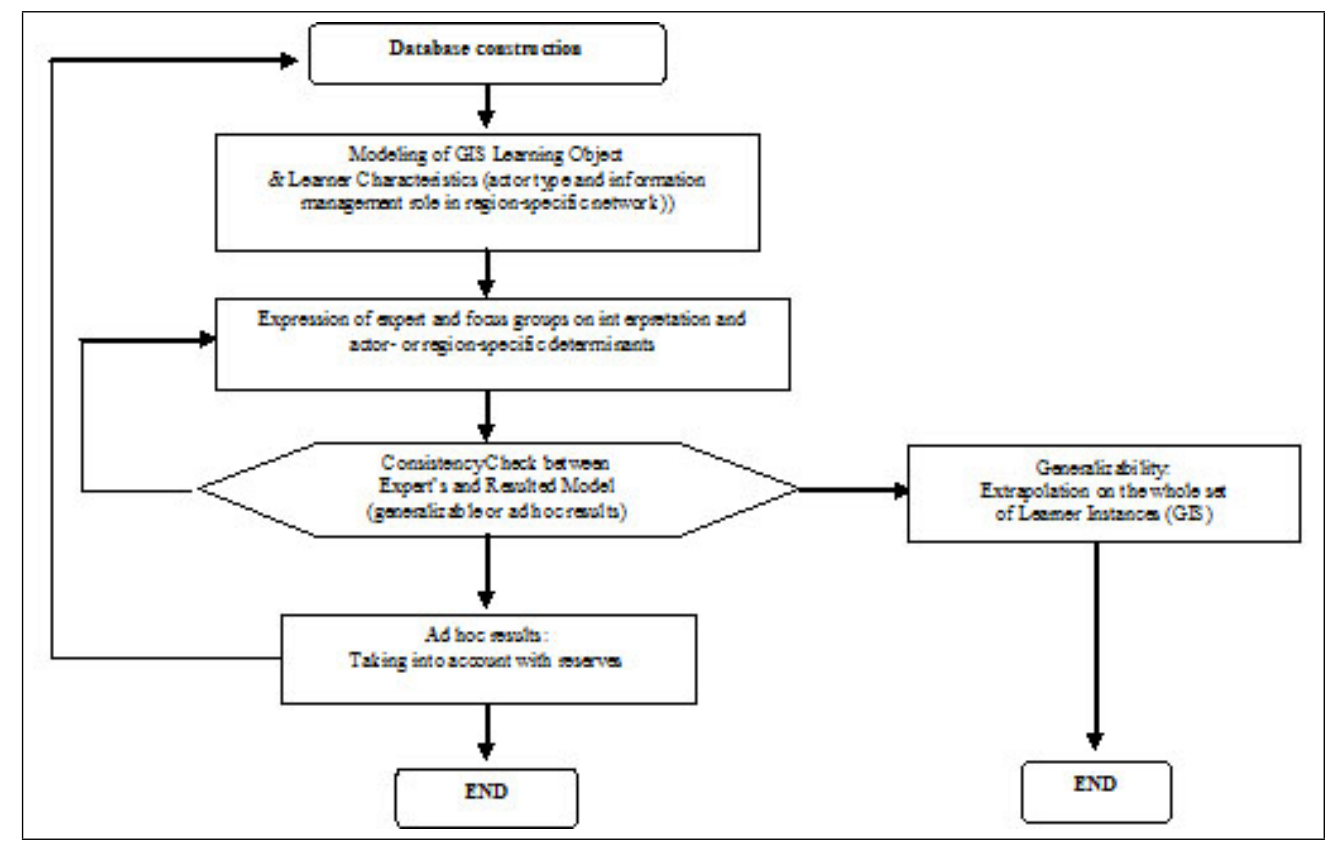

Figure 2: Processing Model Framework.

Each learner can thus examine whether the actor he/she belongs to is a strong "decision-maker" or "postman" in comparison to the other actors, so as to plan his/her lobbying strategy more effectively. In this way, instead of a standardized instructional design, the learner- practitioner (or policy analysis student) can be flexibly oriented by using the $\mathrm{cc}$ and $\mathrm{cb}$ as indicators.

\section{Visualizing "decision-makers" and "postmen"}

Various socio-informatics software products have been used for measuring and visualizing the invisible structures of policy networks which very often include informal relationships [1, 3]. The INSNA web-site ("International Network for Social Network Analysis"- www.insna.org) offers a remarkable variety of such software. However, the implementation and outputs of this software in e-learning through a region-specific GIS Learning Management System is still an open challenge, where the close cooperation of a multi-disciplinary group of social scientists $[13,15]$, software engineers, forest policy analysts, economists and practitioners such as lobbyists, foresters, agrarians etc is necessary. The informal relations are sometimes much more decisive for the policy output than the formal ones $[3,4,7,14]$. A usual relation type in such region-specific networks is the exchange of information [8,9]. The VISONE software is appropriate for depicting and analyzing both formal and informal information exchange. The algorithms of $\mathrm{cc}$ and $\mathrm{cb}$ are used for this purpose. The $\mathrm{cc}$ is an indicator of importance of a policy actor, while the $\mathrm{cb}$ indicates the capacity of controlling the paths of information exchange and thereby the dissemination of "scientific" information [13].

Cc measures the distance d (i.e. the shortest number of links) between two actors. If i.e. the Royal Scottish Forestry Society gives information to the Friends of the Loch Lomond and the latter to the National Trust of Scotland (and there is no direct information link from the Royal Scottish Forestry Society to the National Trust of Scotland), then the distance (d) between the Royal Scottish Forestry Society and the National Trust of Scotland is $\mathrm{d}=2$ (links). The sum of all distances from an actor $\mathrm{i}$ to any other actor is the closeness of the actor $\mathrm{i}$ and then the closeness centrality of $i$ is defined as its inverse closeness $[8,9]$ : 


$$
C c_{(i)}=\left\lfloor\sum_{j} d(j, i)\right\rfloor^{-1}
$$

The fewer links are needed to connect $\mathrm{i}$ to any other actor, the higher its $\mathrm{cc}$ is. If an actor possesses information that is regarded as crucial by the other actors, then one can expect this actor to have a high cc. For this reason, cc is an indicator of the information importance.

$\mathrm{Cb}$ quantifies the information control potential of an actor $\mathrm{i}$ and is defined as the sum of the ratios of shortest paths between other actors that the actor i sits on:

$$
C b_{(i)}=\sum \frac{\left|P_{i}(i, j)\right|}{|P(i, j)|}
$$

where $P(i, j)$ and $P i(i, j)$ are the sets of all shortest paths between $i$ and $j$, and those shortest paths passing through i, respectively. Thus, an actor with high cb plays the role of the "go-between" for many other actors in term of shortest paths and, in this way, controls the dissemination of information. If the actor is also aware of its capability, it can influence the decision-making processes.

$\mathrm{Cb}$ points out the most crucial "postman" of information in a network, while cc shows who is the most important "sender". The "sender" is an information imposer and thereby a "decision-maker" who can directly influence the policy-making. In everyday life, the "sender" (e.g. a bank which makes a decision) may often be clearly differentiated from the person who brings the letter from the bank to the interested client. However, in politics, it is often unclear who the "sender" and who the "postman" is, as these roles are informal. Using the two indicators, cb and $\mathrm{cc}$, this difference can be detected.

Three examples of region-specific networks of "scientific" information flow are presented in Figure 3. These are networks investigating issues like UK1: Management of Loch Lomond and Trossachs National Park, UK2: Scottish Forestry Strategy, and Greece: The amendment of the forest-related Article 24 of the National Constitution Law. The actors are Landowners' Associations, Forest Services, Agricultural Directorates, Cultural Associations (related to nature aesthetics and cultural landscapes), Angling and Hunting Associations, Environmental NGOs, Technical Chambers, Tourist Enterprises, Forest and Agricultural Industries, Municipalities etc (Figure 1 can be used as a legend to understand the nodes in the depicted networks). Number of actors, number of links and the network density (\%) appear in each table cell of Figure 3.

In the first row, the whole region-specific networks appear (two from Scotland and one from Greece). The networks of "scientific" information shaped according to the $\mathrm{cc}$ and $\mathrm{cb}$ of the actors are presented in the second and third row respectively.

The difference of the density degree (\%) between whole contact networks (first row) and this of "scientific" information networks is remarkable: The density of "scientific" information is drastically lower than the "general contact" density, though issues like forest-environment and integrated rural development policy are supposed to be multi-disciplinary areas. Not only the "science"-interested actors are relatively few but the lower degree of density also shows that the "scientific" communication is much weaker than the total activities (e.g. lobbying and institutional pressure, exchange of material support etc) (RUDI findings).

The analysis suggests that in some networks, economic or profit-seeking, private or state actors appear to be the most "important" actors in the "scientific" arena, while universities or research institutes are quite low in importance. This is particularly true for a science-oriented actor (a university) in the UK1 issue. This university is totally excluded from the "scientific" information network. Thus, it is quite subjective which information is regarded as "scientific" (RUDI findings).

Moreover, by comparing the cc with the cb network of the UK2 issue, it becomes obvious that the most influential "decision-maker" is not necessarily the best "postman": A Forest Service possesses the highest cc, while an environmental protection agency possesses the highest $\mathrm{cb}$.

In Figure 4, a comparative view of region-specific scientometric data is provided: Each learner target group can focus its research work on the respective learning object (actor type and position in information hierarchy).

The learners can examine and interpreting the quantitative results: e.g. why the most important "scientist" and "science" controller is the state, why the science-oriented actors are of disputable importance and much weaker in intermediating "science" etc. The e-learning system functions as an "adaptor" which connects the academic knowledge with the practical and "local knowledge". The synergy between field expert experience and academic knowledge can be thereby optimized. Possibilities of coalition building or cross-sectoral over-bridging through science management $[12,14]$ as well as chances for effective coordination through information control $[7,10,15]$ can be discussed and analyzed by all learners. Such an e-learning system could be useful in research projects which aim at the better understanding of rural-environmental policy design, delivery, monitoring and evaluation 
Environmental Policy and Science Management:

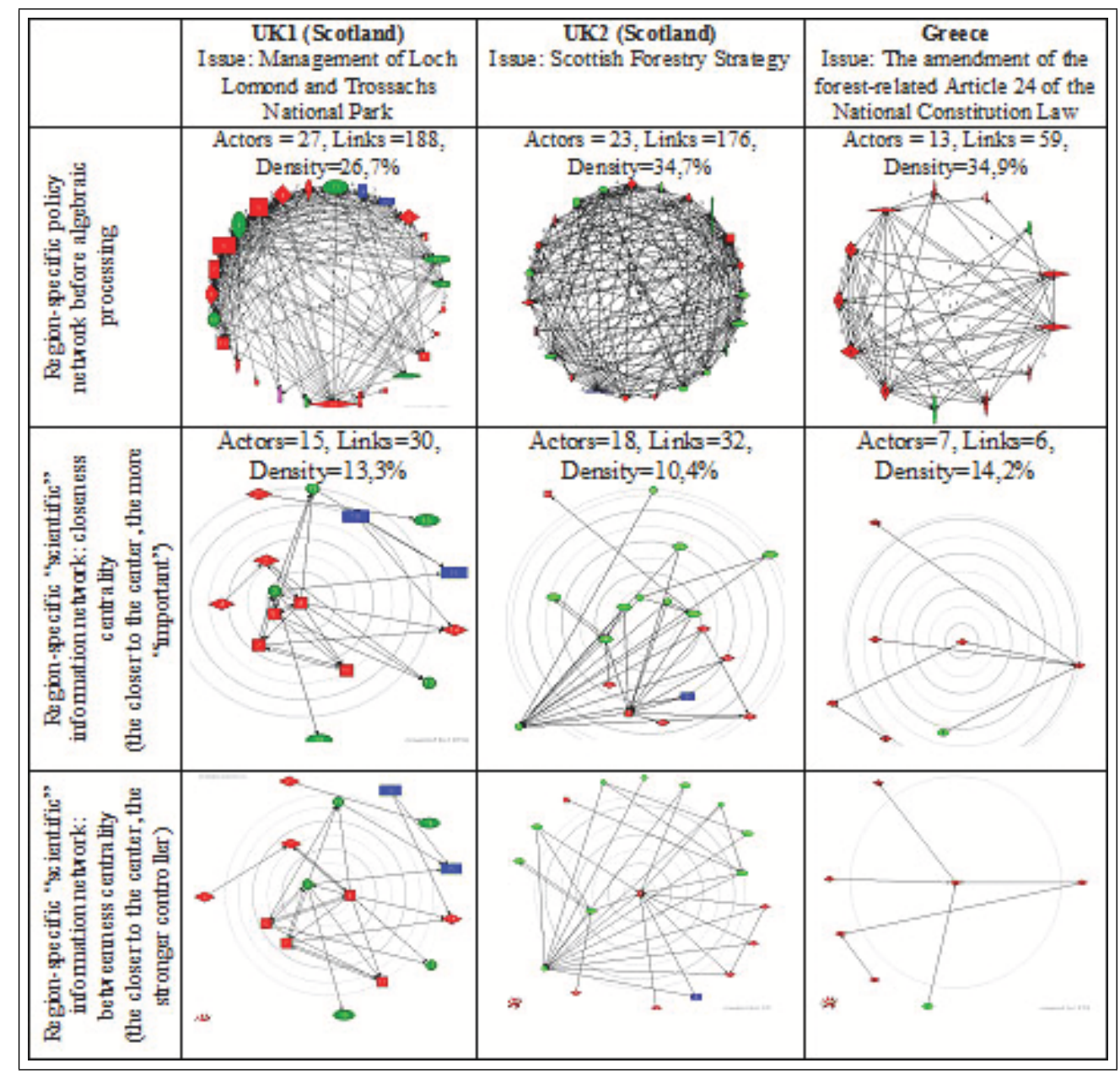

Figure 3: Region-specific networks of "scientific" information flow.

("Archimedes" and RUDI findings). In particular, the implementation of forest policy as a holistic "scientific" toolbox for socio-economic planning, financing and development of forestry, evaluation of the protective and economic role of forest, prediction of supply and demand of forest products and forest administration is enabled.

\section{Summary and Conclusions}

There are different science management patterns among region-specific policy networks. Science-oriented actors are not necessary the leading ones in the information networks which are considered as "scientific" ones by their participants. A scientometric-specific GIS based on complete network analysis helps all learners understand that forest policy, integrated rural development and environmental policy constitute a multifaceted and cohesive politico-administrative system, where the potential influence regarding information use and distribution becomes quite complex and makes the policy output unpredictable. By the presented GIS e-learning system all learner target groups become more familiar with a policy design which takes into account the needs not only of the agricultural population but of a whole integrated rural territory, which is developed in the framework of a new type of urban-countryside relationship (RUDI findings). The quantified learning objects of the integrated rural policy arena should be further interpreted through a participative and qualitative approach. Thereby, the socio-economic and ecological driving forces which determine the quantitative results will be better understood by the learner target groups, independently of any political interests or personal views.

\section{Acknowledgements}

The research initiative proposed by this paper has been supported by the EU-funded research project "Archimedes" 


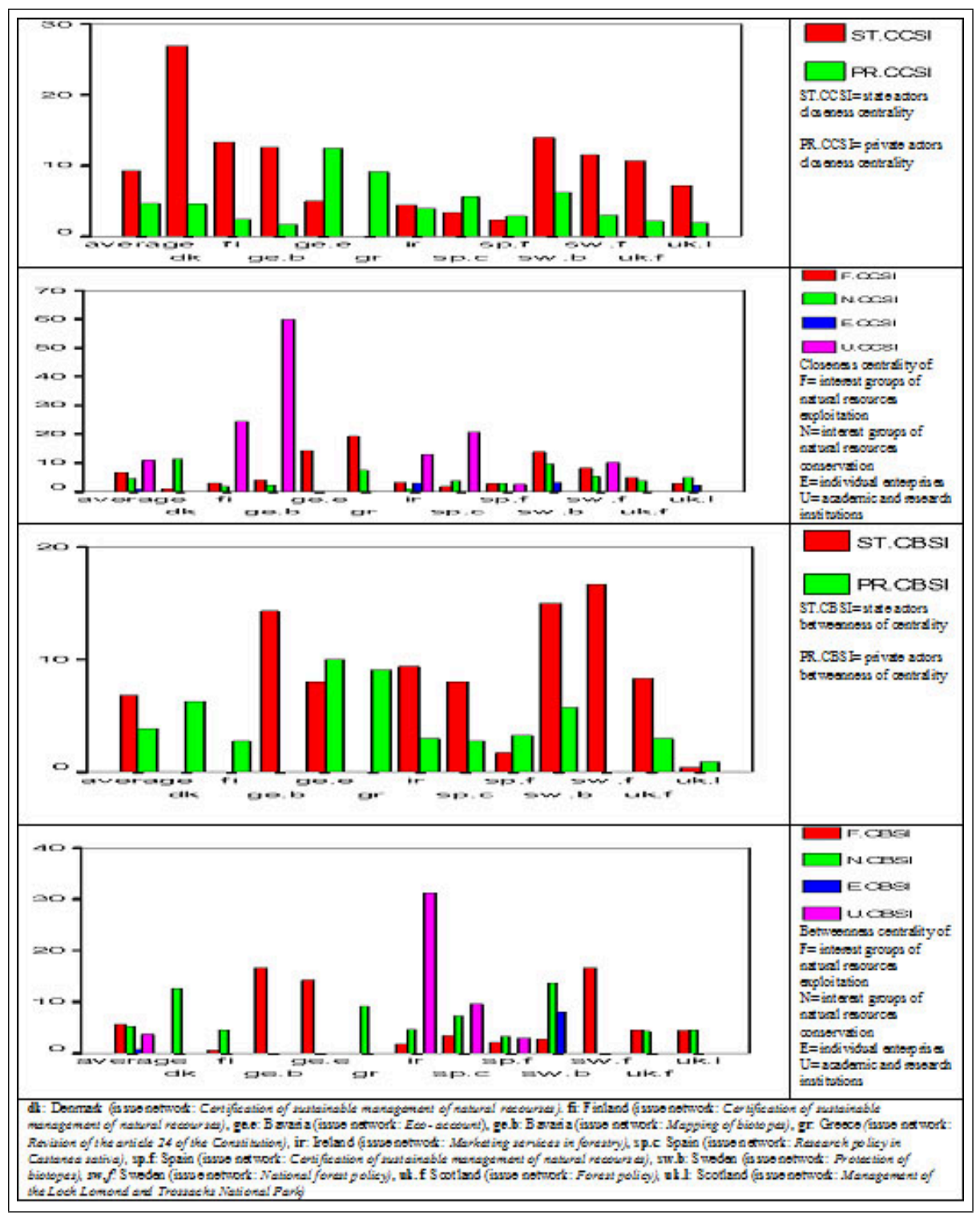

Figure 4: Scientometric- embedded GIS. 
(Department of Landscape Architecture, Kavala Institute of Technology, Drama, Greece), by the EU-funded research project "RUDI: Rural Development Impacts- Assessing the impact of Rural Development policies, incl. LEADER" (Department of Agricultural Economics, Faculty of Agricultural Science, Aristotle University of Thessaloniki, Greece), and by the Institute of Forest Policy and Nature Conservation of Goettingen University (Germany).

\section{Bibliography}

[1] K.A. Bakar, B. S. Doherty, Evaluation of the Recorded State Mechanism for Protecting Agent Integrity Against Malicious Hosts. Int. J. of Computers, Communications \& Control, 3(1), 60-68, 2008.

[2] A.D. Styliadis, I.I. Akbaylar, D.A. Papadopoulou, N.D. Hasanagas, S.A. Roussa, L.A. Sexidis, Metadatabased heritage sites modeling with e-learning functionality. Journal of Cultural Heritage, 10, 296-312, 2009.

[3] M. A. Rajan, M. Girish Chandra, L.C. Reddy, P. Hiremath, Concepts of Graph Theory Relevant to Ad-hoc Networks. Int. J. of Computers, Communications \& Control, 3(S):465-469, 2008.

[4] P. Borne, M. Benrejeb, On the Representation and the Stability Study of Large Scale Systems. Int. J. of Computers, Communications \& Control, 3(S):55-66, 2008.

[5] A.D. Styliadis, D.G. Konstantinidou, K.A. Tyxola, eCAD System Design - Applications in Architecture. Int. J. of Computers, Communications \& Control, 3(2), 204-214, 2008.

[6] A.D. Styliadis, Digital documentation of historical buildings with 3-d modeling functionality. Automation in Construction, 16, 498-510, 2007.

[7] N.D. Hasanagas, Lobbying management: Principles and methods of a more effective practice in the environmental labyrinth of the European Union. Scottish Forestry. The journal of the Royal Scottish Forestry Society. 57(1), 28-32, 2003.

[8] M. Baur, M. Benkert, U. Brandes, S. Cornelsen, M. Gaertler, B. Koepf, J. Lerner, D. Wagner, Visone - Software for Visual Social Network Analysis. Porc. 9th Intl. Symp. Graph Drawing, Lecture Notes in Computer Science 2265, 463-464, Springer, 2002.

[9] A.D. Styliadis, Historical photography-based computer-aided architectural design: Demolished buildings information modeling with reverse engineering functionality. Automation in Construction, 18, 51-69, 2008.

[10] N. Zarour, S. Bouzidi, Coalition Formation for Cooperative Information Agent-Based Systems. Int. J. of Computers, Communications \& Control, 1(3), pp. 85-92, 2006.

[11] A. Andreatos, Virtual Communities and their Importance for Informal Learning. Int. J. of Computers, Communications \& Control, 2(1), 39-47, 2007.

[12] M. Krott, N.D. Hasanagas, Measuring bridges between sectors: Causative evaluation of cross- sectorality. Forest Policy and Economics, 8, 555-563, 2006.

[13] KM. Krott, Catalyst for innovation in European forest policy sciences. Evaluation of the EFI Research Program 3: policy analysis. Forest Policy and Economics, 5(2), 123-134, 2003.

[14] S. Shortall, Are rural development programmes socially inclusive? Social inclusion, civic engagement, participation, and social capital: Exploring the differences. Journal of Rural Studies, 24(4), 450-457, 2008.

[15] D.J.A. Douglas, The restructuring of local government in rural regions: A rural development perspective. Journal of Rural Studies, 21(2), 231-246, 2005.

[16] A.D. Styliadis, I.D. Karamitsos, D.I. Zachariou, Personalized e-Learning Implementation - The GIS Case. International Journal of Computers, Communications \& Control, 1(1), 59-67, 2006

[17] A.D. Styliadis, E-Learning Documentation of Historical Living Systems with 3-D Modeling Functionality. INFORMATICA, 18(3), 419-446, 2007.

[18] A.D. Styliadis, P.G. Patias, N.C. Zestas, 3-D Computer Modeling with Intra-Component, Geometric, Quality and Topological Constraints. INFORMATICA, 14(3), 375-392, 2003. 
[19] A.D. Styliadis, M.Gr. Vassilakopoulos, A spatio-temporal geometry-based model for digital documentation of historical living systems. Information \& Management, 42, 349-359, 2005.

Nikolaos D. Hasanagas Born in 1974. Assistant Professor in environment-related subjects at the Kavala Institute of Technology, Drama, Greece. BSc and MSc eq. in Environmental Sciences (Aristotle Univ. of Thessaloniki, Greece), BA and MA eq. in Social Sciences, PhD in Environmental Policy Analysis (Goettingen Univ., Germany).

Athanasios D. Styliadis Born in 1956. Professor of digital architecture and design computing at the Department of Landscape Architecture at the Kavala Institute of Technology, Drama, Greece. Diploma in Surveying Engineering, MSc in Computer Science (Dundee Univ., Scotland), PhD in CAAD and GIS (Aristotle Univ. of Thessaloniki, Greece).

Eleni I. Papadopoulou Born in 1957. Assistant Professor in Rural Policy at the Faculty of Agricultural Science at the Aristotle University of Thessaloniki, Greece. BSc in Agriculture Engineering, MSc in Agricultural Economics (Univ. of Reading, UK), PhD (Aristotle University of Thessaloniki). 